\title{
COLUMNAR ENTASIS IN VIGNOLA'S AND OTHER RENAISSANCE WORKS
}

\author{
Zuzana GRÚŇOVÁ ${ }^{1,}$, Michaela HOLEŠOVÁ ${ }^{2}$
}

${ }^{1}$ Department of Building Engineering and Urban Planning, Faculty of Civil Engineering, University of Žilina, Univerzitná 8215/1, 01026 Žilina, Slovakia.

2 Department of Structural Mechanics and Applied Mathematics, Faculty of Civil Engineering, University of Žilina, Univerzitná 8215/1, 01026 Zilina, Slovakia.

corresponding author: grunova@fstav.uniza.sk.

\section{Abstract}

Entasis, upward curvature, columnar inclination and several other manipulations or deviations from the strict geometrical rules were known in Ancient Greece and Rome and some of them - entasis could be taken as example - were used up to the beginning of the 20th century in eclectic and historicizing architecture. The article mentions historical texts about entasis from Vitruvius up to Renaissance works. Mainly Vignola's description of proper and elegant way of how to construct columnar entasis curve of the Tuscan and Doric order columns is discussed in detail and expressed mathematically.
\end{abstract}

\section{Keywords:}

Columnar entasis;

Tuscan and Doric columns;

Mathematical description;

Vignola;

The five orders of Architecture.

\section{Introduction}

Entasis, upward curvature, columnar inclination and several other manipulations or deviations from the strict geometrical rules were known and could be found in Greek and Roman buildings from the 6th century BC. Usage is usually limited to dressed stone constructions of the important, highly refined architecture, e. g. sacral one. [1] Entasis is usually described as the convex curve of any vertical architectural member, mainly column. It serves mainly two aesthetic purposes - to attempt to correct the optical illusion of hollowness or weakness that would arise from using the same diameter for the whole column and it could be regarded as attempt to dynamically present actual load on column.

Basic information source about architectural practice in ancient Roman and Greek cultures, although incomplete, is provided by Marcus Vitruvius Pollio, a Roman author, architect, civil engineer and military engineer during the 1st century BC, known for his ten-volume work entitled De architectura. Entasis is mentioned in book III (3.5.15): "These proportionate enlargements are made in the thickness of columns on account of the different heights to which the eye has to climb. For the eye is always in search of beauty, and if we do not gratify its desire for pleasure by a proportionate enlargement in these measures, and thus make compensation for ocular deception, a clumsy and awkward appearance will be presented to the beholder. With regard to the enlargement made at the middle of columns, which among the Greeks is called źvтaбıs, at the end of the book a figure and calculation will be subjoined, showing how an agreeable and appropriate effect may be produced by it." [2] But this "figure and method" appendix to book III was lost probably during the early Middle Ages. Many attempts to reconstruct this procedure began in the 16th century in early printed editions of Vitruvius works, see Fig. 1.

Haselberger [1] also mentions few occurrences of historical, ancient Greek drawings - plans of entasis, incised on the wall (Temple of Apollo, Didyma the 3rd century BC and theatre at Aphrodisias) or pavement (Theatre Temple, Pergamon, the 2nd century AD). Entasis was incised as a section of arc on the reduced height of the column in Didyma and more simplistic approach by linear entasis was used in Pergamon and Aphrodisias. He suggests, that maybe more simpler, routine methods were used in ancient praxis. 

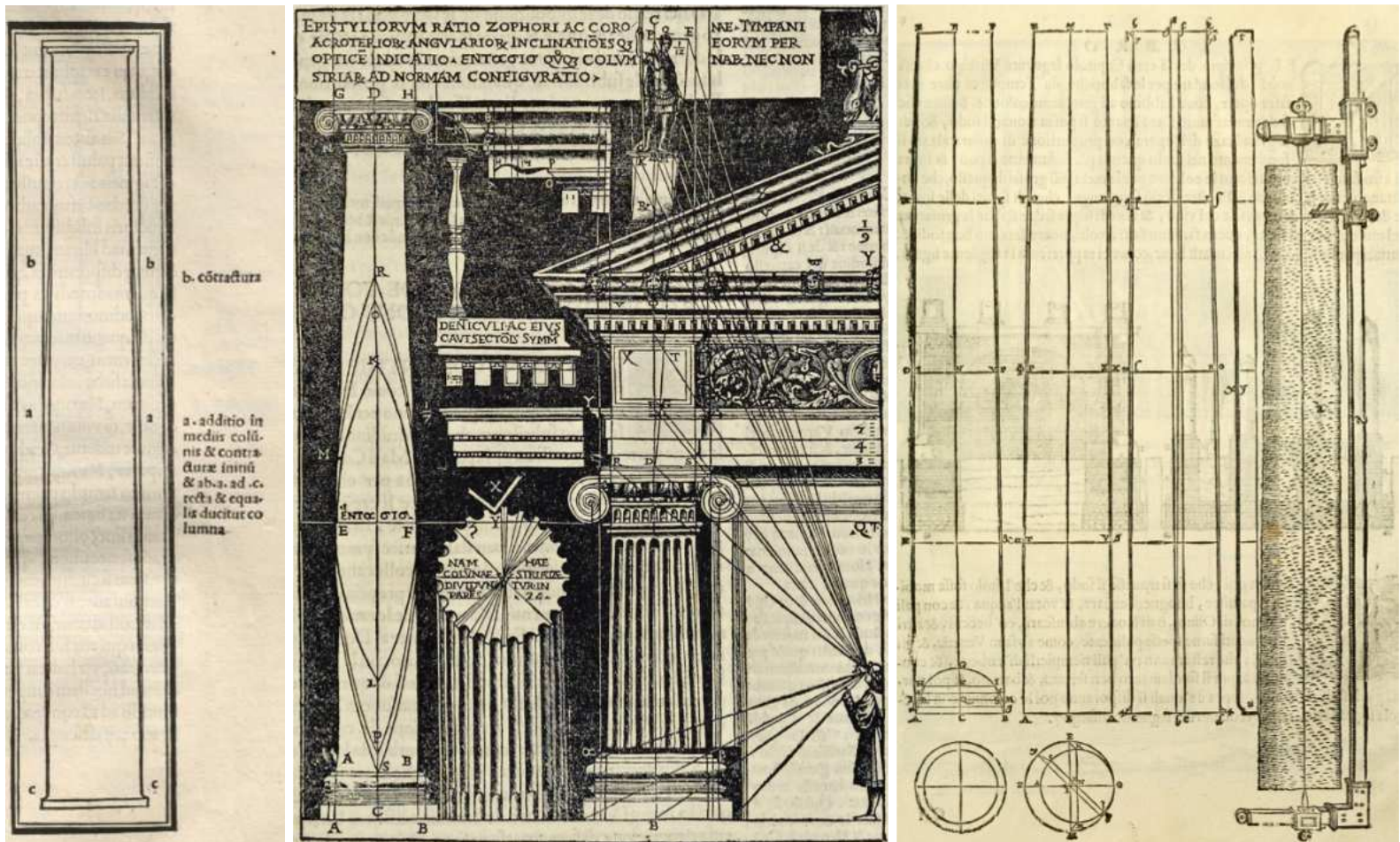

Fig. 1: Some of the many attempts to reconstruct Vitruvius' method for columnar entasis, dated from the left: 1511 [3], the first translation into Italian from the Latin with commentary and illustrations from 1521 [4] and entasis together with method for obtaining columnar inclination from 1660 [5].

Entasis was not entirely lost art in the Renaissance period. Vignola, Serlio, Alberti and Palladio were the most important architect to publish their works, analyses of ancient Roman and Greek architecture and its orders, treatises about proportions, ornament, architectural elements and design a thus they spread the Italian Renaissance style throughout Western Europe. Any echoes of classical approach in architecture up to the 20th century are usually tied to the Ancient Greek and Roman architecture, seen in the light of the Renaissance theories, methods. In many cases these theories were subsequently simplified, or as it will be demonstrated by case of Tuscan and Doric Order - only Doric order proportion ratios were described in the 19th century manual.

Vignola's forms of presentation is the most practical one, result is that his "Canon" is considered as the most published book in architectural history with uncounted copies in spite the original was rather short book of drawings with only short, condensed notes on the subjects depicted. The book was also a part of revival of ancient forms in European and American eclectic and historicist architecture - Vignola's work was e.g. included in editions of The American Vignola by William Robert Ware from 1902.

\section{Barozzi da Vignola and his Five Orders of Architecture}

Giacomo Barozzi da Vignola is one of the great architects of 16th century Mannerism, last period of Italian High Renaissance forms. His name has many variations, Giacomo-Jacopo, Barozzi or Barochio and sometimes he is simply called Vignola, after his birthplace near Modena in Emilia Romagna region of northern Italy. He began to work as an architect in Bologna, then he spent years 1541 - 1543 in Fontainebleau on an invitation from Francis I. [6] King of France was a prodigious patron of arts, who initiated French Renaissance by calling many Italian artists to work on Château de Chambord. Vignola could have met (also Bolognese architect) Sebastiano Serlio. [7] He published two works, earlier one, Regola delli cinque ordini d'architettura - "Canon of the five orders of architecture" was for the first published in 1562, probably in Rome and then published up to date in many various editions in many languages. Original edition has only a few pages of actual text (Introduction) and longer or shorter notes right on the 32 annotated plates (1562). Later editions had more illustrations. The five orders of architecture are presented - Tuscan, Doric, lonic, Corinthian, and Composite, based on Vignola's own measurements of ancient monuments. Descriptions are based on the module chosen by Vignola - radius of the column and all of the other measurements are expressed as 
fractions or multiples of it. Each order has separate sections, subdivided in five parts on the colonnade, arcade, arcade with pedestal, individual pedestals, and entablatures and capitals.

One of the geometrically interesting features of the columns of the orders is their Entasis. Entasis, as described in Renaissance editions of Vignola up to the 19th century, is much more complicated curve with precisely described construction, which is omitted from American editions. Curve is also set differently for simpler orders with more massive proportions - Tuscan and Doric as it is constructed in e. g. Composite order.

Vignola in [8] presented methods of tapering columns Tuscan and Doric (see Fig. 2). Tuscan and Doric order module $M$ (equal to radius of the column) is divided into 12 equal parts "parti" $p$. Height of Tuscan order column is $12 M$, height of Doric order column is $14 M$, base diameter is $2 M$, the same $2 M$ diameter continues up to $1 / 3$ height that means $4 M$ from the base for Tuscan column and 14/3 $M$ for Doric column. Top diameter for Tuscan order column is $M+7 p$ that means $19 / 12 M$. Top diameter for Doric order column is $M+8 p$ that means $5 / 3 M$. When comparing these columns at the same $2 M$ diameter, the Doric column is $2 M$ higher and $1 / 12 M$ wider in the top diameter than Tuscan column.

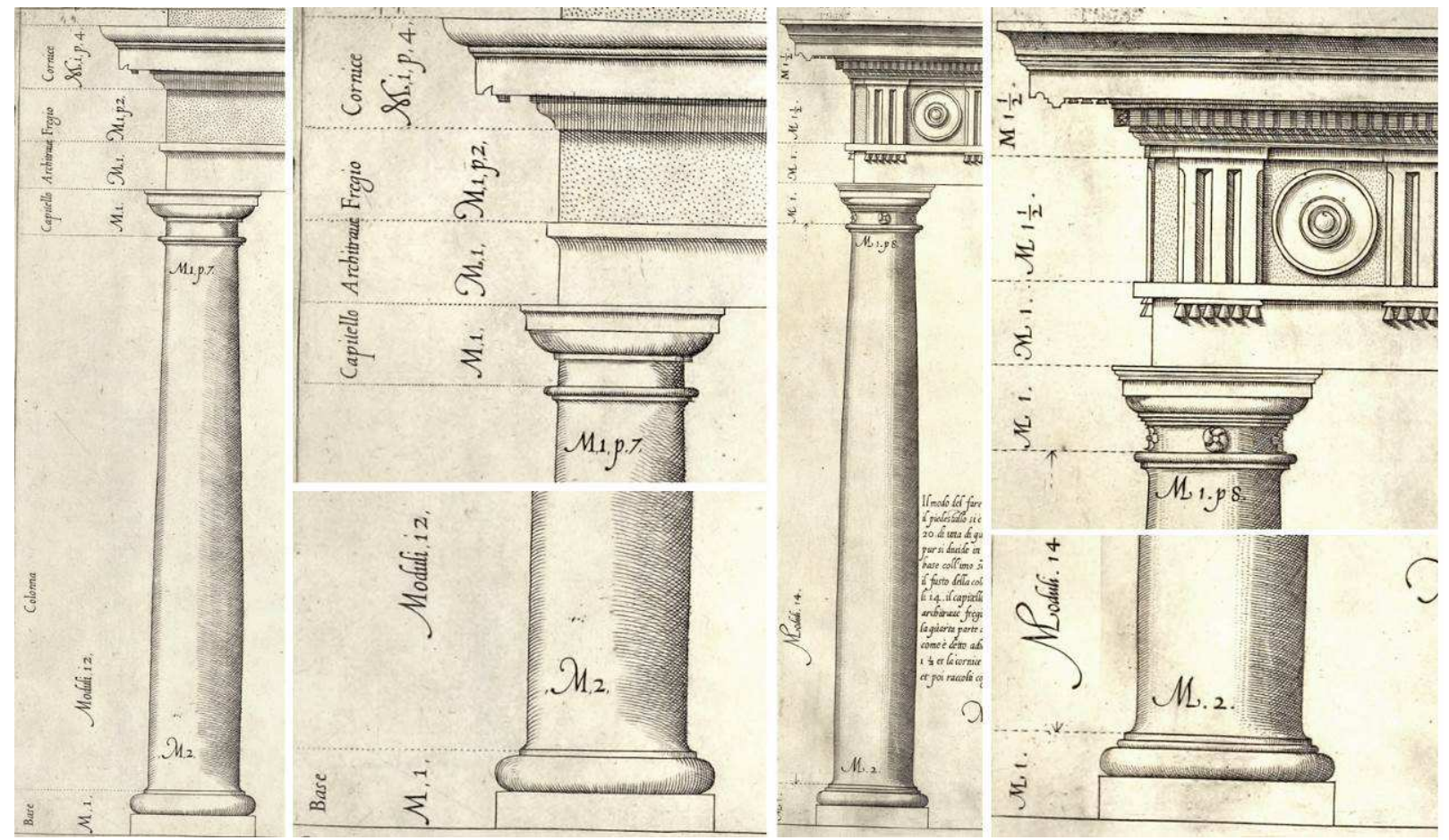

Fig. 2: Tuscan (left) and Doric (right) order and its moduls, Plate IIII, V and VIII of [8].

Vignola in [8] also described how to construct Entasis of the Tuscan and Doric order columns in general, regardless of the parameters for the individual columns already described before, on the separate folio of the Canon (see Fig. 2): "Salsi in piu modi il sminuire delle collonne, de quali ne pongo qui duoi accettatti per, i, migliori. Il Primo et piu noto si'e, che 'terminata l'altezza, et la grossezza della colonnae, et quanto si uvole che sminuischida la terza parte in su; si forma un semicircolo a basto doue cominicia il sminuire, et quella parte che ne uie compresa dalla linea perpendiculare del sómo stape; quaste dividendola in quante parti equali si uuole, et in altrestanto partendo li duoi terzi della colonna, et poi accordando le linee perpendicolari, con le transversali, sarano trouati li soitermini come si uede in figura. Di questa forma colonne si puo usare nel Toscano et nel Dorico." (see Fig. 3a).

Description Vignola's construction of the Entasis, but concretized only for parameters of Doric columns, appeared in the English edition, published 327 years after the original Canon [9]: "Methods of Tapering Columns [Tuscan and Doric]. At a point 1/3 from the bottom draw a horizontal line across the center line of the column, and with the point of intersection as a center describe a semicircle. From this point the column is tapered upward. Divide the height into any number of equal parts. From the end of the top diameter of the column, which is 5/6 of the diameter at the bottom, drop a perpendicular upon the semicircle at the point $D$. Divide the arc DE into the same number of equal parts as is the upper part of the column. From each one of these points erect a perpendiculars to the division lines 
across. The points of intersection will be points on the surface of the column. The points $F$ show the intersections, and the points $G$ the outline." (see Fig. 3b).

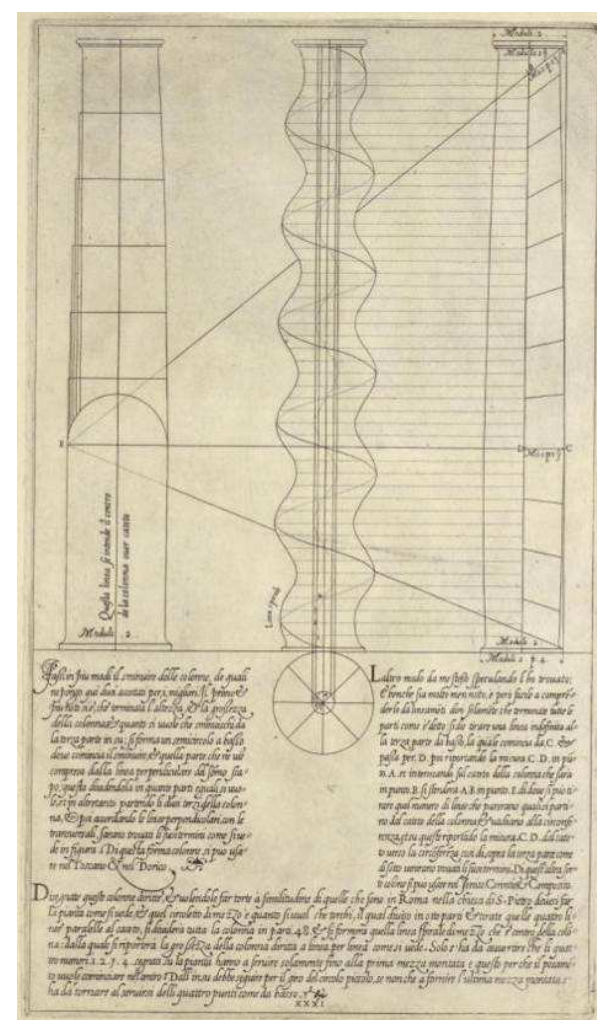

a)

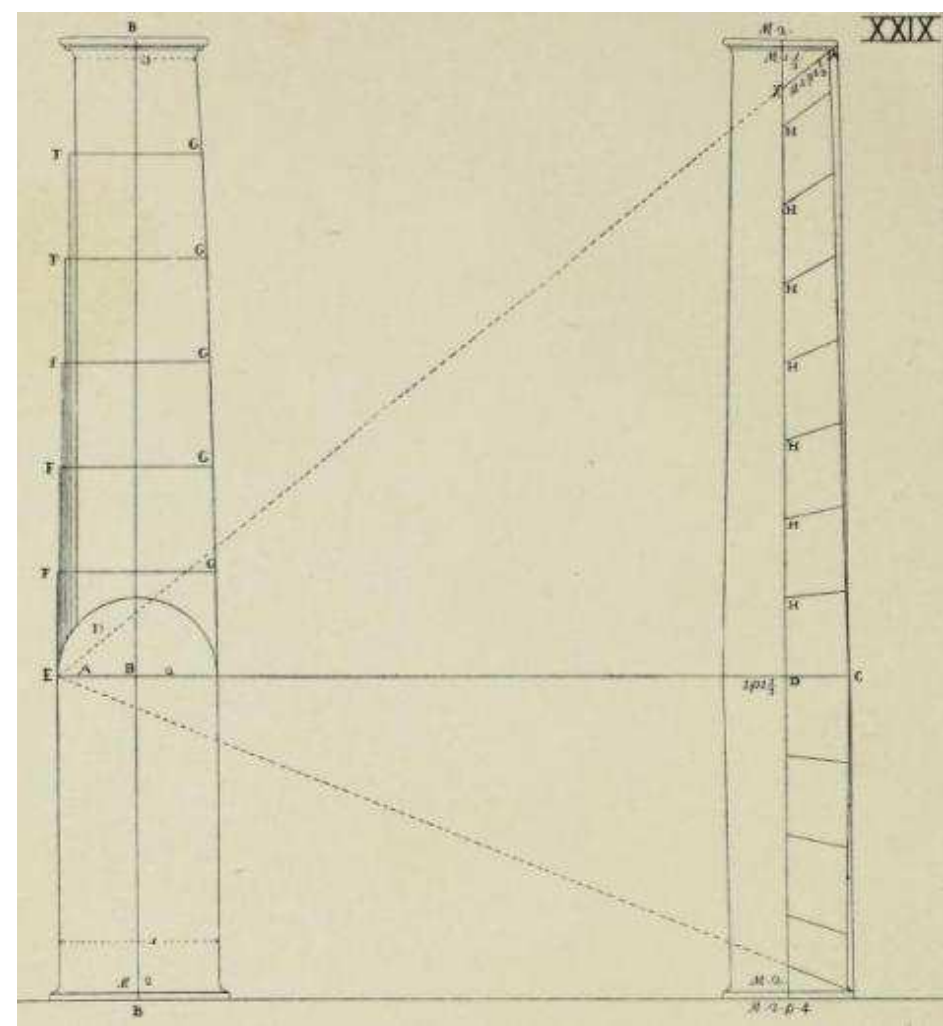

b)

Fig. 3: a) Entasis of the columns and construction of helical columns from Vignola's Canon, 1563, Plate XXXI [8]; b) Two methods of "tapering Columns": suitable for Tuscan and Doric columns (left), construction of the conchoide used for Composite and Corinthian orders (right). Source [9].

Depending on the module $M$ the column diameter is $2 M$ and $5 / 6$ of the diameter $2 M$ is therefore equal to $5 / 3 M$, which corresponds to the Doric column parameters in this description. For the Tuscan column is procedure of the construction the same, with the column height being $12 \mathrm{M}$ and the top diameter being $19 / 12 \mathrm{M}$.

In Fig. 4 are drawn all constructions - general construction and both Tuscan and Doric column Entasis. Denoted points are the intersections as $F_{i}$ and points $G_{i}, i \in\{1,2, \ldots, 6\}$ are the points on contour of the entasis. The segment $E K$ is $2 / 3$ of the column height, divided into the identical parts, in this case 6 . The entasis contour curve can be mathematically described on the basis of the construction using the analytical geometry.

The angle $E S D$ equals $\operatorname{arcos}\left(\left|O G_{6}\right| /|S E|\right)$. Parametric equations of the circle with the center $S$ and the radius $|S E|$ are

$x=|S E| \cos t, \quad y=|S E| \sin t, t \epsilon<0.2 \pi)$.

The arc $D E$ can be expressed following on (1):

$x=|S E| \cos t, \quad y=|S E| \sin t, t \epsilon<0, \operatorname{arcos}\left(\left|O G_{6}\right| /|S E|\right)$. 


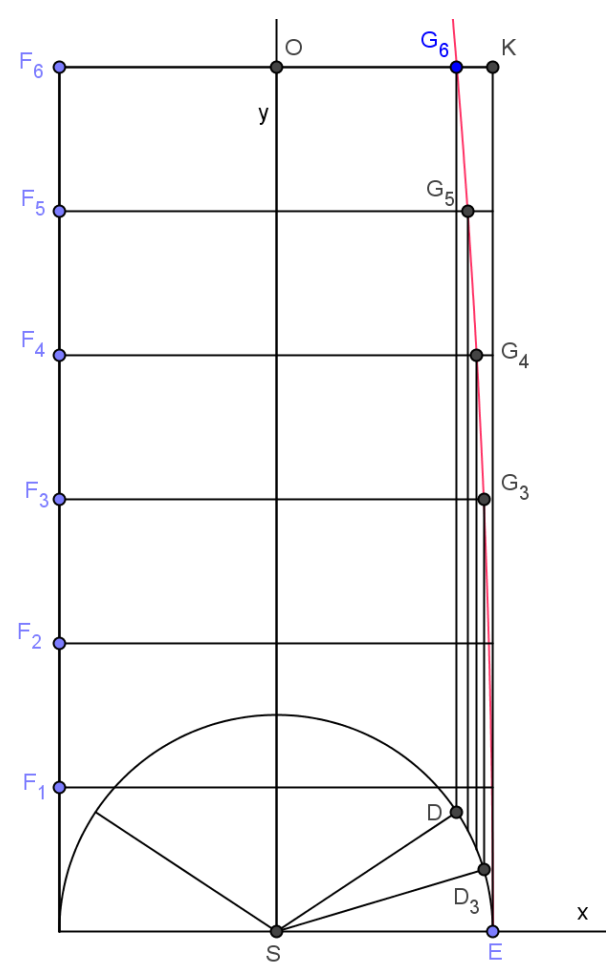

a)

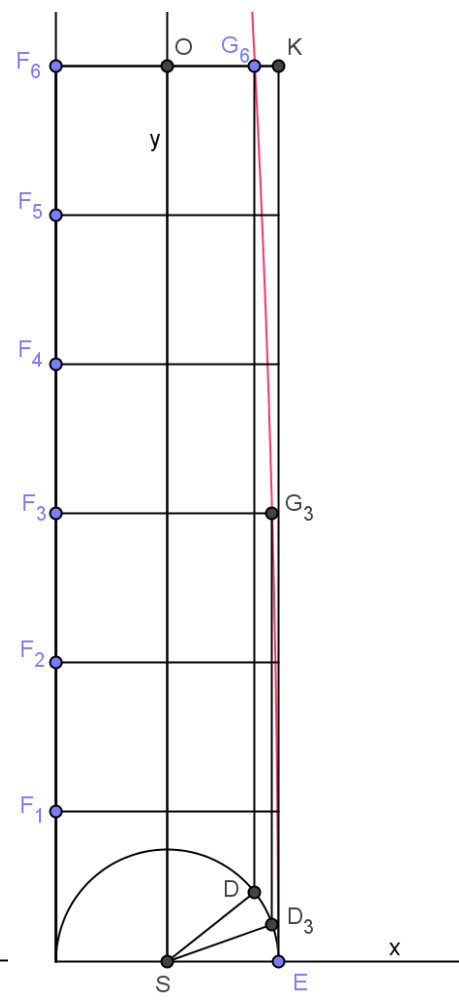

b)

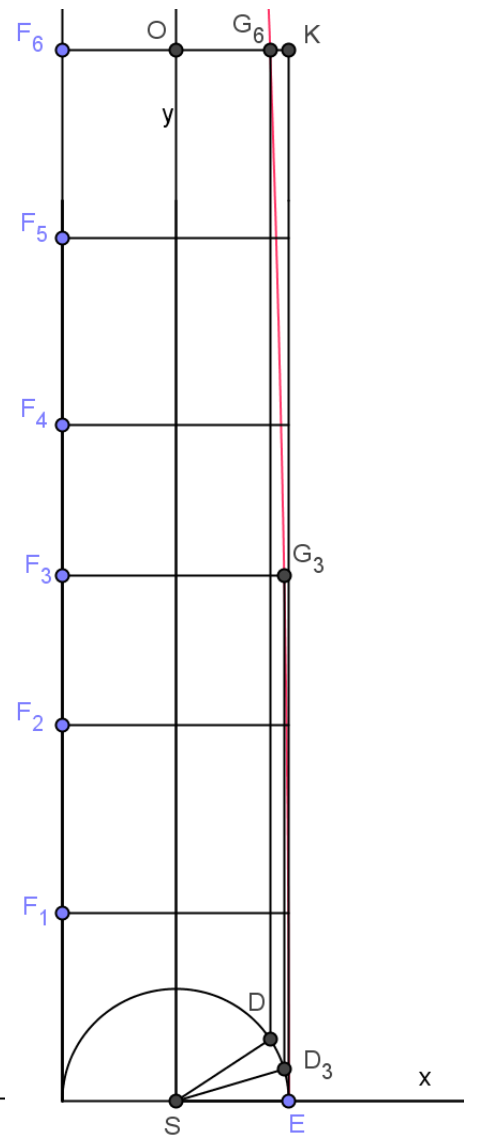

c)

Fig. 4: a) General construction; b) Tuscan column; c) Doric column (only 2/3 of the columns height are drawn, created by Holešová).

The $x$-coordinate of the point $G_{i}$ is equal to the $x$-coordinate of the point $D_{i}$ on the circular arc $D E$. Points $D_{i}$ are constructed as described in the construction, thus dividing the circular arc $D E$ into the same number of parts as the $E K$ segment is divided. The construction shows that the $y$-coordinate of the point $G_{i}$ and $F_{i}$ are the same. Therefore

$t: \operatorname{arcos}\left(\left|O G_{6}\right| /|S E|\right)=y:|K E|$

and the coordinates of the point $G_{i}[x, y]$ of the contour are

$x=|S E| \cos t, \quad y=t|K E| / \operatorname{arcos}\left(\left|O G_{6}\right| /|S E|\right), t \epsilon<0, \operatorname{arcos}\left(\left|O G_{6}\right| /|S E|\right)$.

This entasis contour curve can be expressed also explicitly in (5) and it is a graph of the goniometric function (drawn in red in Fig. 4).

$x=|S E| \cos \left(y \operatorname{arcos}\left(\left|O G_{6}\right| /|S E|\right) /|K E|\right)$.

Expression for the Tuscan column could be expressed as (6) and for Doric column see (7).

$x=M \cos (y \operatorname{arcos}(19 / 24) /(8 M))$,

$x=M \cos (3 y \operatorname{arcos}(5 / 6) /(28 M)$.

For the general construction in Fig. 4. a) was chosen diameter of column $4 M$ and the height of the column $12 M$, so the entasis would be more visible. The top diameter is $5 / 3 M$, while in this case $M$ equals to one and a half times the unit of measurement. For all the columns in Fig 4, the same $M$ is selected. 
If the module $M=300 \mathrm{~mm}$ is chosen (structurally and architectonically reasonable), than following previous equations with this module - the diameter $2 M$ equals $600 \mathrm{~mm}$ and the Doric column will be constructed as $600 \mathrm{~mm}$ higher and $25 \mathrm{~mm}$ wider in the top diameter than the Tuscan column.

\section{Conclusion}

Relatively simple and clear graphic construction procedure for Tuscan and Doric order column entasis was considered in the Renaissance as a more difficult than sophisticated construction of lonic and Corinthian column entasis. Maybe because of this reasons it was gradually simplified - original separately given parameters for height/width etc. of the Tuscan and Doric order columns were unified to one procedure for both, based on the Doric Order parameters during period of 300 years separating the first publication of the Vignola's Canon (1562) from the English version of 1889. Also it seems, considering the examples mentioned in [1], that constructional theories of entasis were simplified to lines or arcs even in the ancient praxis. During the research of this theme - method of geometric construction and mathematical expression of Dorian column entasis - it became necessary to rely only on Renaissance sources, as the ancient ones were not preserved (are not known). Among the current authors, Haselberger [1] provides the most comprehensive approach to reviewing construction methods documented on ancient Greek buildings.

Mapping the use of entasis on built examples from Renaissance to present is an appropriate subject for further research. It seems that to a large extent, especially in the case of constructions from the 20th century, the shape of the columns is not constructed, but builders use already pre-calculated dimensional templates. An example of such an approach is a period revival of ancient forms in historical American architecture - Vignola's work was included in editions of The American Vignola by William Robert Ware from 1902. [10]

\section{References}

[1] HASELBERGER, L.: Appearance and Essence: Refinements of Classical Architecture--Curvature. UPenn Museum of Archaeology, 1999, pp. 22 - 35.

[2] VITRUVIUS: The Ten Books on Architecture. Harvard University Press, London: Humphrey Milford, Oxford University Press, 1914, http://www.perseus.tufts.edu/hopper/text?doc=Vitr.\%203\&lang= original.

[3] VITRUVIUS, P.: M. Vitruvius per locundum solito castigatior factus ... lannes de Tridino. McGill University Library, Toronto, 1511, https://archive.org/details/McGillLibrary-rbsc_blc_m-vitruvius-perlocundum-solito_folioNA2517V71511b-2998.

[4] VITRUVIUS, P. - CESARIANO, C. - GALLO, A. - PIROVANO, A. - GIOVIO, B. - MAURO, B.: Di Lucio Vitruuio Pollione De architectura libri dece ... di epsa opera. Getty Research Institute, No. 9929975880001551, 1521, https://archive.org/details/gri_33125008262210.

[5] RUSCONI, G. A. - PIOBBICI, S.: I dieci libri d'architettvra by Vitruvius, 1660, https://archive.org/ details/idiecilibridarch00vitr.

[6] FROMMEL, S.: Vignola in Francie: un episodio incerto del suo itinerario artistico. Studi su Jacopo Barozzi da Vignola, 2011, eds A. M. Affani and P. Porthoghesi, Rome, Gangemi, 215 - 36.

[7] Encyklopædia Britannica, https://www.britannica.com/biography/Giacomo-da-Vignola.

[8] BAROZZI da VIGNOLA, G.: Regola delli cinqve ordini d'architettvra, 1563. Getty Research Institute, Americana Collection, call No. 108109, https://archive.org/details/gri_33125008229409. Plate XXXI.

[9] VIGNOLA, G. - JUGLARIS, T. - LOCKE, W.: The five orders of architecture. 1889, pp. $34-35$, https://archive.org/details/fiveordersofarch00vign.

[10] WARE, W. R.: The American Vignola, 1904: https://archive.org/details/americanvignola00 vigngoog; edition of 1902: https://archive.org/stream/ cu31924091026504\#page/n19/mode/2up. 